\title{
LIVRO-BOI SEM TRIPAS: O PAÍS DE BENJAMIN SANCHES É UMA CIDADE GUARDADA POR SERPENTES DE FOGO
}

\author{
OX-BOOK, SERPENT-BOOK: BENJAMIN SANCHES'S \\ COUNSTRY IS A CITY GUARDED BY FIRE SERPENTS
}

Priscila Lira de Oliveira (UFPR)

priscilaliradeoliveira@hotmail.com

\begin{abstract}
RESUMO: Este texto oferece uma proposta de leitura do conto "O Miolo" (1998), de Benjamin Sanches, imersa no espaço construído pelo autor. As cidades onde vivem suas personagens, claramente inspiradas nos municípios interioranos amazonenses, carregam consigo a floresta como vizinhança. Desse modo, buscamos encontrar nessa narrativa a presença da selva nas cidades, da mesma forma como nossa sociedade se faz tão presente na Amazônia (a partir de pesquisas, da exploração vegetal e animal e de projetos de ocupação religiosa, dentre tantos outros); encontramos, então, no subsolo uma possível resposta. Ao mesmo tempo que seres míticos habitam a terra desses cenários, sua influência na superfície emerge sempre causando bruscas alterações na realidade das personagens, afrontando, assim, a suposta autonomia dos indivíduos que se creem já civilizados e modernizados. À parte a forte influência greco-romana na obra do autor, ao evocar cenas claramente dionisíacas, gostaríamos de pontuar a também forte relação de seus temas com conhecimentos que habitam a floresta amazônica.
\end{abstract}

PALAVRAS-CHAVE: Benjamin Sanches, Boiúna, Amazonas, Boi-Bumbá, Boitatá

\begin{abstract}
This text proposes to read the short story "O Miolo" (1998), by Benjamin Sanches, immersed in the space built by the author. The cities where his characters live, clearly inspired by the Amazonian rural municipalities, carry the forest within itselfs as a neighborhood. Therefore, we seek to find in this narrative the presence of the jungle in the cities, in the same way that our society is so present in the Amazon (due to researchs, plant and animal exploration, and projects of religious occupation, among many others); we find, then, a possible answer in the underground. At the same time that mythical beings inhabit the land of these scenarios, their influence on the surface always emerges, causing sudden changes in the reality of the characters, thus confronting the supposed autonomy of individuals who believe they are already civilized and modernized. Apart from the author's strong Greco-Roman influences, by evoking scenes that are clearly Dionysian, we would like to point out the strong
\end{abstract}


relationship between Sanches' themes and the knowledge that also inhabits the Amazon rainforest.

KEYWORDS: Benjamin Sanches, Boiúna, Amazonas, Boi-Bumbá, Boitatá.

\section{Introdução}

Conta-se, em muitas cidades da Amazônia brasileira (como Itacoatiara, no Amazonas, e Belém do Pará) uma história na qual ninguém acredita. Apesar disso, ela é capaz de, ao menos durante os períodos dedicados a ouvi-la - principalmente ao passarmos em frente à principal igreja do lugar -, transformar o solo em abrigo de uma cobra com proporções colossais, podendo botar toda a construção do município abaixo em instantes - a começar por provocar rachaduras nas paredes do templo religioso (OLIVEIRA, 2014). A Cobra Grande não é a única narrativa oral envolvendo serpentes amazônicas que ainda faz parte do imaginário popular: Boitatá segue preenchendo o seleto grupo de mitos ameríndios replicados nas escolas brasileiras, e sua relação com o fenômeno do fogo-fátuo - produzido a partir de matéria orgânica encontrada na beira dos rios que, ao entrar em combustão, forma serpentes de fogo azul que desaparecem rapidamente (também presente no processo de putrefação de cadáveres) - faz da história um ótimo exemplo de transdisciplinaridade entre literatura oral e ciência.

Gostaria de me apropriar de algumas imagens produzidas por essas histórias para falar da relação entre um contista amazônico e os ecos do modernismo presentes na literatura amazonense, habitando seu subsolo e produzindo, assim, pequenos terremotos e focos de incêndio na cidade e na floresta. A publicação de O Outro e Outros Contos, em 1963, está quarenta anos distante da I Semana de Arte Moderna e bastante próxima da floresta amazônica. Enquanto os modernistas buscam renovar nossa rica mitologia a partir das cidades concretas, como indivíduos crescidos nessa paisagem, Benjamin Sanches encontra, aí, portas e caminhos abertos para falar de tantas histórias enterradas debaixo dos centros urbanos amazônicos e que se renovam logo ao lado, no ainda vasto verde que os rodeia.

Verde que, já naquela época, era abrigo, além de índios, ribeirinhos, grileiros, seringueiros, fazendeiros e mineradores, de muitos bois (e onças, macacos, pássaros, peixes, capivaras, insetos, cachorros e diversos felinos). Sanches, assim como os modernistas, fala a partir da cidade. Mas é preciso também que encaremos a proximidade dessa cidade, mundo do 
autor, com a selva como um traço a ser observado em suas narrativas. Suas personagens transitam constantemente entre a mata densa e as feiras, as mercearias, os salões de beleza e os hospitais. Voltar à floresta não lhes parece tão difícil quanto para Macunaíma (2013 [1928]), de Mário de Andrade. Mas é depois de Macunaíma e Cobra Norato (BOPP, 1931) que se forma um terreno relativamente fértil para a publicação do amazonense.

Podemos enxergar, de um lado, o Modernismo se construir dentro de uma cidade encrustada de mitos e, do outro, O Outro e Outros Contos surgir dentro de uma floresta encrustada de bois. Boi bovino e boi, que pode ser o prefixo de cobra em tupi, de onde surgem termos como Boiuna (Cobra Grande) e Boitatá (Cobra de Fogo).

o amor ao bicho gritava: bôôôoi!

ali estava o centro dos mundos seus, deixando transparecer as emoções sentidas e incompreendidas. era vê-los arrebentando a noite, numa caravana de toadas de barulhos e ruídos estranhos, no rolar de vozes que o tempo cobrira de fuligem. o dizer do canto dava o anonimato de serpentes de fogo com as quais lutavam sem as ver nem escutar. (SANCHES, 1998, p. 100)

As personagens do conto "O Miolo" só veem o boi; são cegas para as serpentes de fogo abrigadas e agindo no submundo de suas histórias (SANCHES, 1998, p. 99). Há uma distância e uma proximidade tão estranhas ao pensamento ameríndio - as cobras de chamas agem pelo contato, pela luta - ao ponto de transparecer um conflito entre diferentes dimensões no mesmo espaço. De um lado, temos os festivos e gritantes participantes da festa, agindo violentamente sobre a noite por meio de ruídos estrondosos; do outro, esse mesmo canto funciona como evocação intuitiva, anônima de uma serpente/labareda - confundindo-se com as "tochas acesas" (SANCHES, 1998, p.100) -, que age, também, violentamente sobre os brincantes, sem que esses a "vejam", tomem dela consciência.

É comum às suas narrativas a sobreposição visual entre os planos físico e espiritual; do mesmo modo, humanos carregando fortes características animais, ou até incorporando-os, brotam aqui e ali. Entre bovinos e tartarugas, as personagens se movem e modificam a si mesmas e aos outros. Mas a presença e a imagem da serpente carregam mais que essas possessões: elas são as responsáveis pelos laços e trançados entre os dois planos, parecendo, por isso, amalgamar um conhecimento invisível, aparentemente inorgânico, que se espalha pela cidade e pela floresta.

Essas relações não são nada pacíficas: comumente, os múltiplos planos são sobrepostos em situações limiares, de iminência da morte, ou dela propriamente dita. Em alguns casos, esses 
momentos coincidem com celebrações festivas banhadas a sangue humano. O cenário sacrificial dá o tom das construções desses corpos indefinidos entre homem/mulher e outros animais; é preciso um dilaceramento físico para que essas unidades de misturem. Todavia, dentro de seus limites, estão sempre se esbarrando.

Há, então, duas características comuns ao livro de Benjamin Sanches - mas não só: comuns também ao pensamento de quem vive na floresta, ou mesmo aos mitos que dão origem a nossa sociedade ocidental - a serem introduzidas aqui: a relação entre contexto sacrificial e acesso ao mundo mítico (aquele onde humanos e animais se conversam, misturam e negociam) e a concepção do corpo como algo que se desmonta e remonta a partir da relação com o espaço e com outros corpos (humanos, animais, vegetais, espirituais). A partir disso, farei uma leitura do conto "O Miolo", buscando compreendê-lo como encenação da experiência literária dentro de um país fundamentalmente ameríndio.

Pedro Cesarino, no texto Corporalidades Heterotópicas (2016), traça uma linha mitológica que passa por Grécia, Índia, Espanha e México, chegando à filosofia clássica e moderna, para demonstrar a profundidade de algumas histórias pertencentes às sociedades amazônicas, quando relacionadas a uma compreensão do corpo como elemento reorganizável e desmontável. Todos esses lugares utilizam a imagem do corte, do esquartejamento, para falar dessas remodelagens. Dionísio é reduzido a cinzas para, então, ser refeito; Ganesha tem a cabeça decepada para ganhar seu rosto de elefante.

\begin{abstract}
As imagens artísticas e divinas antes mencionadas são, efetivamente, modos de figuração do corpo que colocam em risco a unidade do ser humano, que comprometem a sua autonomia e individualidade. Falaremos aqui desse desafio ou, em outras palavras, de configurações do corpo que oferecem um contraponto à estabilização do indivíduo humano característica do Ocidente. Trataremos, mais especificamente, de modos de hibridização, de composição e de recomposição do corpo que indicam um estatuto ontológico do humano diferente daquele marcado pela distinção entre natureza e cultura e suas derivações. (CESARINO, 2016, p. 159-160)
\end{abstract}

Para os povos Ianomâmi e Marubo, exemplificados por Cesarino, essa dimensão mítica não habita apenas as narrativas de tempos imemoriais. Técnicas corporais dominadas pelos xamãs os tornam aptos a também acessar esse espaço e se conectar com outros corpos, não sem que passem, antes, por uma série de experiências bastante dolorosas, como jejum, dietas rigorosas, isolamento, abstinência sexual, ingestão de psicotrópicos - uma desmontagem. Para os xamãs, essas são experiências de morte, que podem trazê-los de volta, marcados pelo renascimento. 
Outra característica atravessada por essas narrativas é a construção de carcaças, máscaras animais utilizadas com o fim de incorporar alguns traços desses bichos. Desde as bacantes (história também invocada em "O Miolo") até, extrapolando o texto de Cesarino, os mitos de origem dos grafismos Kaxinawa (LAGROU, 2007), utiliza-se pele de animais, ou a simulação destas para ter acesso a visões outras que a do paramentado em seu estado humano. O conto de Benjamin Sanches transforma a personagem alma em um boi de festa, atravessado por uma faca e uma serpente de duas cabeças (formada pelo caminho traçado entre os chifres e o rabo) que se confunde com seu corpo.

\footnotetext{
na enfermaria o clorofórmio vai esvaindo-se e, pouco a pouco, os golpes começam a comichar, transformando-se em leves dores que, morosamente, ajudam a ressurgir a fulguração do espírito.

recorda-se que era o miolo, e, o miolo, a alma dele. os chifres, ornados com flores $e$ dois bem ajeitados laços de fita, traçavam espirais que se enroscavam no bolor da noite, em movimentos cadenciados, que se evaporam e desciam, mansamente, para uma pausa de vírgula. recobrando o fôlego, subiam num furor de cólera, deixando o rabo passar bem rente ao chão.

o veludo alvonegro acolchoava a armação de ripas, vazia de estrume, que, a passos lentos, era levada pelos pés da alma. a estrela na testa, ora descia ora erguia-se dentro da bola de luz formada por uma dezena de tochas, queimando o querosene e abrindo a passagem onde se acotovelava toda aquela gente, cujas avelhantadas canções, aplicadas no novo tempo, saíam cozinhadas de calor para se resfriarem na neblina da noite. (SANCHES, 1998, p. 99-100. Grifo meu.)
}

Miolo é o preenchimento da roupa, a pessoa que dará vida ao bovino festivo, característico das festas de boi-bumbá. Curiosamente, a personagem não chega a ser nomeada em nenhum momento; ficamos com a alcunha de "alma". Mais à frente, o narrador comenta que a festa deixa os brincantes fora de si, e alma, após o golpe que a joga para a fronteira entre a vida e a morte, alcança o limite desta saída do próprio corpo. Ao entrar no corpo do boi, sendo mulher, a personagem já praticou um ato de corte profundo na realidade: todas as personagens do boi-bumbá costumavam ser interpretadas por homens, inclusive as femininas, como Catirina. Essa transformação atinge o corpo de alma através da massa amorfa do público: não sabemos o autor do golpe, que a remove bruscamente do que ainda lhe restava de unidade, ou autonomia. Removida do corpo do boi, alma é devolvida a si mesma no hospital, onde segue tentando sobreviver até o fim do conto.

No livro Contos de Sagração, Nicia Zucolo (2011) dá a ver a estrutura sacrificial que atravessa as narrativas d'O Outro e Outros Contos (1998), usando o episódio de "O Miolo" para pontuar uma dessas ocorrências. Há, para a autora, uma associação da festa com a liberação temporária de um processo de cristianização vitorioso, momento fictício de retorno ao tempo mítico (a animalização) até que, enfim, dê-se um sacrifício real no meio do caminho. 
Calcando-se nessa ideia, pode-se, então, afirmar que o ciclo estava completo: a festa tinha cumprido sua função de aplacar a fúria da multidão mediante o sacrifício do boi, morto pelo desejo de carne, vencido pela ressurreição de um corpo físico, travestido de animal. (ZUCOLO, 2011, p. 101)

Citado por Cesarino (2016), o texto das Bacantes, de Eurípedes, guarda bastante semelhança com a passagem final de “O Miolo". Nela, os brincantes, assim como as seguidoras de Dionísio, vão se transformando em feras conforme sua embriaguez evolui, ao ponto de ferirem a carne de alma, possuídas pelo desejo de sangue vindo da terra. Não fosse o hospital, o conto de Sanches poderia ter-se tornado uma narrativa de canibalismo. Há, claramente, a intervenção do mundo civilizado, ou da medicina ocidental, com o intuito de devolver a unidade de alma e extirpar o sofrimento bovino da personagem.

êêeh boi.

por baixo, a alma mortal e, ao derredor a gente boa e obreira, transformando-se em feras devorando feras, para no escorrer da realidade da luta, rangendo os dentes e fervendo no crime atroz, ferir a carne que a terra espera num desejo demoníaco.

êeêh boi. êêe boi. (SANCHES, 1998, p. 101)

O espaço mítico aberto pelo ferimento do miolo une, no mesmo contexto, o imaginário fundador da cultura ocidental, o imaginário popular criado a partir da cultura agropecuária e o imaginário indígena, o mais sutil, caracterizado pela serpente de fogo citada ao início dos festejos e pelo desenho da cobra de duas cabeças, formado, por sua vez, pelos chifres, coluna e rabo do boi, capazes de unir, nas duas extremidades, noite e chão. Há outros entrelaçamentos entre o boi/cobra e o boi-bumbá, além do nome compartilhado. Jeremy Narby (2018) demonstra, em sua pesquisa a respeito do uso xamânico da Ayahuasca, a importância atribuída pelos xamãs a uma serpente, aparecendo, às vezes, com duas cabeças, detentora e difusora do conhecimento universal. Além disso, ela é também responsável pela ligação entre diferentes planos, como material e espiritual, terrestre e celeste. Benjamin Sanches posicionou-a perfeitamente na paisagem noturna.

Além disso, a própria cerimônia do boi-bumbá segue princípios semelhantes a mitologias que relacionam a serpente ao conhecimento dos grafismos indígenas. Do mesmo modo que alma adentra as vísceras vazias do boi, sendo assim tratada como um, algumas histórias contam de personagens que trançam vestes de cobra para adquirir determinadas características em contextos de crise social, ou que são seduzidas, possuídas por serpentes, adquirindo, com isso, talentos como a arte dos desenhos geométricos. Do mesmo modo que o 
boi das festas de boi-bumbá anda sobre duas pernas, algumas serpentes xamânicas, de acordo com Narby (2018), também se movimentam desse modo, com pernas humanas. Sendo assim, podemos dizer que alma, além de boi e ela própria, torna-se, também, uma serpente, vinda para ensinar sobre a inclusão das mulheres no teatro de Catirina e Pai Francisco, fato corriqueiro nos dias de hoje, onde muitas personagens femininas (cunhã-poranga, sinhazinha, morena bela, porta-bandeira) são alvo de adoração do público nas festas de boi-bumbá?

Elsje Lagrou (2007), no livro A Fluidez da Forma, reúne uma série de mitos Kaxinawa contando sobre as relações ancestrais entre a jiboia e a arte do desenho. A princípio, isso se deve ao aspecto de trançado de suas escamas e à beleza das imagens por elas criadas e, até mesmo, ao modo como ela se move. A jiboia ensina esse povo a produzir desenhos, redes, cestarias, sendo responsável tanto pelo caráter utilitário, quanto estético dos objetos.

\begin{abstract}
A agência da jibóia se manifesta através do aumento da capacidade da visão; ela (ou ele) passa aos humanos a capacidade de gerar desenho e o desenho fornece a moldura e a condição para a geração de qualquer tipo de forma. Essa ideia será extensivamente ilustrada com exemplos no texto a seguir. Quero por ora questionar a lógica da predação aqui proposta: será que a jibóia é realmente um bom representante da alteridade para os Kaxinawa?

Uma possível resposta será encontrada no mito do grande dilúvio. Enquanto o resto da humanidade e dos artefatos desapareceu ou se transformou em animal, um casal, deitado em rede com desenho, se transformou em sucuri. Este é também o mito de origem da humanidade atual. Somente uma mulher sobreviveu. Nete, que deu luz aos primeiros novos humanos. A consubstancialidade de humanos e da grande jibóia/sucuri já era, portanto, dada no mito. Isto é, a sucuri já foi humana, e mais, era a combinação de um homem e uma mulher que estavam fazendo amor quando surpreendidos pelo dilúvio: a cobra mítica ou o yuxin da jibóia/sucuri combina agência feminina e masculina. A humanidade na sua forma atual, por outro lado, só foi produzida depois do dilúvio. Neste sentido, sucuris e humanos são realmente muito diferentes; a interação entre estes diferentes tipos de seres implica em perigos inerentes ao lidar com a alteridade e se dá nos termos da predação: mata-se a jibóia. (LAGROU, 2007, p. 74)
\end{abstract}

Ao mesmo tempo que o animal é parte fundamental da produção do conhecimento histórico e artesanal dos Kaxinawa, modelando corpos e utensílios, produzindo significações ritualísticas, sua alteridade é sempre um perigo. Foi se vestindo de sucuri que seus ancestrais aprenderam a desenhar, ou se salvaram do dilúvio. Além disso, a figura da cobra também aparece em outros contextos: ela pode se caracterizar aos modos de uma pessoa e seduzir um Kaxinawa para o seu mundo. Por isso é preciso reafirmar as posições predatórias. Costuma-se sacrificar uma cobra durante a iniciação de uma artesã nos grafismos (LAGROU, 2007). Da mesma forma, alma, enquanto voz de um conhecimento (serpente), digamos, feminista, 
contrasta com o restante do elenco, e sua diferença é reafirmada a partir do sacrifício. O que ela ensina, no entanto, passa a fazer parte, de fato, da festa do boi-bumbá.

Foucault (2013), no seu Corpo Utópico, transforma em texto nossa inapreensibilidade sobre nossa própria unidade. Pensar nos limites do próprio corpo seria dilacerá-lo, posto que jamais poderíamos nos observar em terceira pessoa, ou perceber a nós mesmos a partir de outro. A única saída mora também na saída de si, a partir do extremo contato com o fora: no sexo, o limite máximo de transbordamento dos nossos contornos. O corpo seria, então, uma utopia, pois a sua unidade é inalcançável. Nossa relação com o mundo nos quebra em partes; só vemos, de nós mesmos, mãos e pernas soltos no espaço, se movendo e movendo outros corpos, objetos. Tanto o contato quanto a ausência dele são violentos. E, na floresta, a relação de seus habitantes ancestrais (que costumam se enxergar como unidade coletiva: "nós" e o "outro lado", "nós" e "os brancos", "nós" e "o contrário") com o outro, o visitante, o explorador, o catequizador ou colonizador, é bastante tensa - isso o sabemos, todos.

Em "O Miolo" de Sanches temos, então, uma mulher: alma, vestida como miolo do boi. Esse boi, de veludo alvinegro e chifres ornados com coroas de flores, é atravessado pela imagem de uma serpente de duas cabeças - de origem ancestral e xamânica, comum aos iniciados dos rituais ayahuasqueiros -, que liga a narrativa a um tempo mítico, não apenas greco-latino, mas também ameríndio. Afinal, estamos falando de uma cidade ficcional, fincada dentro da floresta amazônica.

Sanches também foi certeiro ao colocar a festa do boi-bumbá em um contexto bastante carnavalesco, de praticamente histeria coletiva, dada a gravidade do crime ocorrido. A evolução dessa celebração na Amazônia, principalmente em Parintins (AM), adquiriu muitos traços do carnaval carioca, inclusive em relação ao número de turistas. Candace Slater (2001) comenta a respeito do soterramento de uma série de relatos orais mitológicos da região a partir da modernização do festival; pouco ainda se guarda em relação à lenda do boto e suas variações e aos espíritos das matas e dos rios, chamados de encantados, ainda vistos, raramente, por algum observador atento, ou inventor de histórias.

Os ornamentos chamativos e a gritaria embriagada, em contraponto às misteriosas serpentes que se movem nas sombras da narrativa, diz muito da visibilidade dessas figuras no espaço do imaginário popular. Entretanto, ambos os bois, Garantido e Caprichoso, principais concorrentes do festival (destacados dos demais da cidade), dedicaram canções e alegorias ao Boitatá e à Boiuna ao longo dos anos. De modo que, até nos festejos reais, as serpentes fazemse presentes e recebem homenagens. 
Gostaria, então, compreendendo a metamorfose de alma em boi e serpente, de sugerir um possível desdobramento ao título da narrativa. Alma (não sabemos ao certo se é esse o nome da personagem, ou a função que ela desempenha na festa), ou o miolo do boi, ocupa um lugar que poderíamos caracterizar como bem semelhante àquele da cobra no subsolo da cidade: serpenteando embaixo da carcaça, é ela quem movimenta o boi, causando, assim, em interação com o público, também deslocado da normalidade, o próprio dilaceramento.

Experimentamos sentimento semelhante no ato da leitura, se pensarmos que o miolo do livro, assim como o boi-bumbá, não tem vísceras próprias: precisa das nossas para dar movimento aos cenários e personagens que o compõem. Aos modos de alma, dilaceramos nossa unidade de sujeitos ocidentais a fim de animar vidas feitas a partir do tecido do papel. Vestimos os livros, esquartejados em quantos personagens ele suportar, e saímos a serpentear por nossa realidade com as palavras de outrem, com o conhecimento que nos foi dado graças a essa incorporação. Nós somos o miolo, e ele, o miolo do livro, a carcaça da serpente.

Enquanto isso, Cobra Norato repousa embaixo da cidade d'O Outro.

\section{REFERÊNCIAS}

ANDRADE, Mário. Macunaíma: O Herói sem nenhum Caráter. Rio de Janeiro: Nova Fronteira, 2013.

BOPP, Raul. Cobra Norato. São Paulo: José Olímpio, 2008.

CESARINO, Pedro de Niemeyer. Corporalidades Heterotópicas: Montagens e Desmontagens do Humano nos Mundos Ameríndio e Além. Revista Brasileira de Psicanálise, São Paulo, v. 50, n. 2, p. 158-175, 2016.

FOUCAULT, Michel. O Corpo Utópico, As Heterotopias. São Paulo: N1 Edições, 2013.

LAGROU, Elsje. A Fluidez da Forma: Arte, Alteridade e Agência em uma Sociedade Amazônica (Kaxinawa, Acre). Rio de Janeiro: Topbooks, 2007.

OLIVEIRA, Ariana Silvia Souza de; AMBRÓSIO, Millana C.; GAVIRATI, Vitor F.; NEVES, Soriany; PESSOA, Sue Anne G. Cursino. Cobra Grande. Belém: Intercom, 2014.

SANCHES, Benjamin. O Outro e Outros Contos. Manaus: Valer, 1998.

SLATER, Candace. A Festa do Boto: Transformação e Desencanto na Imaginação Amazônica. Rio de Janeiro: Funarte, 2001. 
ZUCOLO, Nicia. Contos de Sagração. Manaus: Valer, 2011.

ANEXOS

o miolo

Organon, Porto Alegre, v. 36, n. 72, p. 210-222, jul/dez. 2021.

DOI: $10.22456 / 2238-8915.116672$ 
toda vez que a alma retorcia-se na dor, os padioleiros procude operação. as enfermeiras substituíam a roupa conduzi-la à sala angue e terra, pela branca esterilizada do hospital, enclada de suor, eraminava o ferimento. não havia tempo para o processo de identificico ficha ficaria em branco até a defloração do espaço.

- teremos que operar. o golpe é profundo e é de natureza grave.

aquelas palavras tiveram um sentido de ordem e ordem expressa. os seus auxiliares movimentavam-se com maior rapidez e os panos alvos passaram a recruzar a sala ao som do retinir do aço.

- um, dois... cinco... e perdeu-se no mundo do anestésico. o bisruri, em dedos ágeis, fez crescer o furo quase um palmo e as compressas tingiam-se de sangue novo. a lâmina do punhal havia varado o lombo do corpo e, depois de penetrar entre as costelas do miolo, perfurou-the a base do pulmão direito. fora a graveza daquela estocada que a fizera tombar sob a estrutura. minutos após, quando serenaram os ânimos, destacaram-na do corpo e trouxeram-na para o hospital.

na enfermaria o clorofórmio vai esvaindo-se e, pouco a pouco, os golpes começam a comichar, transformando-se em leves dores que, morosamente, ajudam a ressurgir a fulguração do espírito.

recorda-se que era o miolo, e, o miolo, a alma dele. os chifres, ornados com flores e dois bem ajeitados laços de fita, traçavam espirais que se enroscavam no bolor da noite, em movimentos cadenciados, que se evaporavam e desciam, mansamente, para uma pausa de vírgua. recobrando o fôlego, subiam num furor de cólera, deixando o rabo passar bem rente ao chão.

0 veludo alvonegro acolchoava a armação de ripas, vazia de 
estrume, que, a passos lentos, era levada pelos pés da alma. a estrela da testa, ora descia ora erguia-se dentro da bola de luz formada por uma dezena de tochas, queimando o querosene e abrindo a passagem onde se acotovelava toda a(jucla gente, cujas avelhantadas cançōes, aplicadas no novo tempo, siáam cozinhadas de calor para se resfriarem na neblina da noite.

o amor ao bicho gritava: bôôôi!

ali estava o centro dos mundos seus, deixando transparecer as emoçòes sentidas e incompreendidas. era vê-los arrebentando a noite, numa caravana de toadas de barulho e ruídos estranhos, no rolar de vozes que o tempo cobrira de fuligem. o dizer do canto dava o anonimato

de serpentes de fogo com as quais lutavam sem as ver nem escutar.

na molhadura das vestes caminhavam mastigando a noite. somente ela de mulher. até a catirina era homem, homem-mulher do chico-tira-língua.

todos sempre quiseram ser o que estavam sendo naquela explosão anual do depósito de suas memórias e pensavam que os outros não mais existissem. de olhos incendidos, encapelavam-se de subúrbio para subúrbio, sem nenhum encontro marcado e, de quando em quando, a toada de desafio mordia o espaço:

se tem medo sai da frente

eu pisei e torno a pisar

pisarei no boi valente

que meu rumo atravessar.

sem pressenti-lo, caminhavam para o saco da luta. era a psicolodivertia massa carregando, na música, os brincantes, para se arriscarem no va os pertimento que os jogava fora de si mesmos, dentro da fúria que sopraabrir uma vala no escuro da hora, para sepultarem os seus prazeres.
andios e o arminho da seda dos vaqueiros. pareciam 


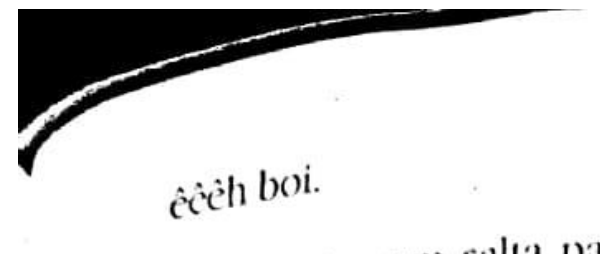

o globo de som salla para o ar, enculanto outra esfera de luz naç no preto, devorando a distância numo doido festim fatal. mistunares no preto, do dos bandos embriagados no gargalhar da orgia, do
nam-sc luze édio inconscientes, iniciando a sagração inútil do gládio.
annor e odio

ềèh boi.

por baixo, a alma mortal e, ao derredor a gente boa e obreira, transformando-se em feras devorando feras, para, no escorrer da realidade da luta, rangendo os dentes e fervendo no crime atroz, ferir a carne que a terra espera num desejo demoníaco.

êêêh boi. êêêh boi.

e a febre queimando a carne da alma.

Artigo submetido em: 10 jul. 2021

Aceito para publicação em: 14 set. 2021

DOI: https://dx.doi.org/10.22456/2238-8915.116672 